\title{
Development of an Automated Measurement System for Dilution Process and Spraying Amount of Disinfectant
}

\author{
Jung-Chul Kim ${ }^{1}$, Sun-Ok Chung ${ }^{1}$, Byoung-Kwan $\mathrm{Cho}^{1}$, Hong-Hee Chang ${ }^{2}$, Suk Kim ${ }^{3}$, Dongil Chang ${ }^{1}$ \\ ${ }^{1}$ Department of Biosystems Machinery Engineering, Chungnam National University, Daejeon, Korea \\ ${ }^{2}$ Department of Animal Bioscience, Gyeongsang National University, Jinju, Korea \\ ${ }^{3}$ College of Veterinary Medicine, Gyeongsang National University, Jinju, Korea
}

Received: August $8^{\text {th }}, 2013$; Revised: August 24 ${ }^{\text {th }}, 2013$; Accepted: October $23^{\text {rd }}, 2013$

\section{Abstract}

Purpose: The objectives of this study were to develop an automated disinfectant dilution system, and an automated data management system for spraying amount for resolving uncertainty problem. Methods: Proper diluting rate was made by a controlled volume pump for liquid disinfectant and a screw conveyer pump for solid disinfectant. The water capacity of disinfecting system of $400 \mathrm{~L}$ was controlled by two water level sensors. The water quantity of water tank was controlled by the signals which were produced by the water level sensors. Signals were processed by Labview Programming, and ON/OFF of solenoid valve that was used for controlling water supplying to water tank, was controlled by SSR. The operating time of pumps for disinfectant was controlled quantitatively. A turbine flowmeter was used for development of automated measurement system for spraying amount of disinfectant. In order to save the flowmeter data and to control the spraying system, a multi-function data logger was used, and it was processed and saved in Excel file by a program developed in this study. Results: Labview 2010 was used for programming to control the automated measurement system for spraying amount of disinfectant. Results showed that the relationship between flowmeter value and time had a significant linear relationship such as 0.99 of $\mathrm{R}^{2}$. Generally, $6.74 \mathrm{~L} / \mathrm{s}$ of diluted disinfectant is sprayed for a vehicle passing through the disinfection system (about 15 seconds). Test results showed that average error between the measured spraying amount and the flowmeter data was $50 \mathrm{~mL}$, and the range of error was $1.3 \%$. Since the amount and time of spraying could be saved in real-time by using the spreadsheet files which could not be modified arbitrarily, it made possible to judge objectively whether the disinfection spraying was performed or not. Test results of spraying liquid and solid disinfectant showed that the errors between the measured discharge rate and the theoretical one were ranged within 3-4\% for various dilution rates. Conclusions: The disinfection system developed would be working accurately. The automated spraying data base management system satisfied the purpose of this study. The automated dilution process system developed in this study could discharge liquid and solid disinfectant with accurate dilution rate, relatively.

Keywords: Automated measurement system, Controlled volume pump, Dilution process, Disinfectant, Disinfection system, Screw conveyor pump, Spraying amount

\section{Introduction}

Currently in domestic livestock industry, the annual total production of swine, cow and poultry have reached 12 trillion won, and its portion holds the second rank

\footnotetext{
*Comesponding author: Dongil Chang

Tel: +82-42-821-6718; Fax: +82-42-823-6246

E-mail: dichang@cnu.ac.kr
}

after rice production in Korea. The scale of Korean livestock industry has been increased. For swine industry, 6.79 million heads in 1997 increased to 9.8 million heads in 2010, and for the cow, 1.9 million in 2007 to 2.7 million in 2010. Whereas the number of household of small scale livestock farm has been decreased, that of medium and large scale one has been increased sharply (KSAM, 2012). Since the scale and management of livestock farm 
becomes large, specialized, and industrialized, the facilities of livestock farming have been mechanized and automated. As the results of such processes, the number of livestock per caretaker was increased and eventually it became difficult to manage and examination minutely for swine, cattle, and poultry. Owing to this situation, the possibility of disease occurrence might be increased, and it was worried that there was a good possibility of spread on a large scale, if it were occurred.

Currently, the major diseases occurring in livestock farm domestically are foot-and-mouth disease, brucellosis, swine fever, and AI, and these disease are occurred by various pathogenic organisms. Due to those diseases, the compensation expenses of stamping out and the costs of preventive measures of disease have run into astronomical figures.

The amount of damage owing to major diseases occurring in livestock farm, was estimated as 2.6 trillion based on the compensation expenses of stamping out from 2005 to 2011. And the amount of damage owing to foot-and-mouth disease occurring recently was estimated more than 3 trillion, and the damages by diseases have been increasing.

Currently we are experiencing some problems of less disinfection and more disinfection in domestic livestock farms, that are occurring by the improper dilution rate of disinfectant. The less disinfection takes a serious turn of disease, while a more disinfection causes environmental pollution of spraying area, and due to the loss of disinfectant, economical and temporal damages are occurring seriously.

Also currently, because foot-and-mouth disease and AI are taking serious turn, the livestock farms are conducting disinfection using spraying equipment under the regulation of disinfection. But, there is uncertainty problem whether disinfection has been conducted thoroughly at farm level.

\section{Dilution processing system for disinfectant}

Cho and Kahng (1993) developed a precise automatic dispenser/diluter controlled by a personal computer. For the diluter developed, they used a step motor as a power source, and that was interfaced by the Programmable Peripheral Interface (PPI, 8255A) board with PC to be controlled. The minimum amount of dispenser developed was $0.012 \%$ of volume of syringe, and its precision and accuracy were less than $0.4 \%$, respectively, within the range of dispensing.

A dilution system was developed by Park et al. (2011) for calibration of the electrochemical sensor, In the tests, when calibration gas inserted directly to sensor without passing diluter, the results showed that the accuracy of dilution was less than $90 \%$ of the required concentration. But when the diluter developed was used, results showed that the dilution ratio was precise to the required one more than $98 \%$.

Salmonella and brucella have been inducing serious disease to livestock, and causing great economical damage to livestock industry as well as food industry. Cha et al. (2012) studied bactericidal efficacy of vital-oxide, disinfectant solution against salmonella typhimurium and brucella ovis. In their study, they used broth dilution method, and exposed salmonella typhimurium and brucella ovis to various levels of diluted disinfectant at $4{ }^{\circ} \mathrm{C}$ for 30 minutes, and selected the most efficient and the lowest dilution rate of disinfectant by the test results.

\section{Flow rate measurement system}

For the flow rate measurement by non-contacting technology, Kwon et al. (2009) showed the test results that the non-contacting radar surface velocity meter had outstanding performance in terms of velocity measurement and stability, even though accuracy was a little bit debased, comparing with other methods. But, for resolving the accuracy problem, they strongly suggested using the compensating factor, that is existing between surface velocity and average velocity of radar surface velocity meter. If it would be supplemented, the accuracy would be improved.

In altitude engine test, the most significant factor that affecting the uncertainty of fuel flow measurement of a turbine flowmeter (Figure 1), was the dispersion of

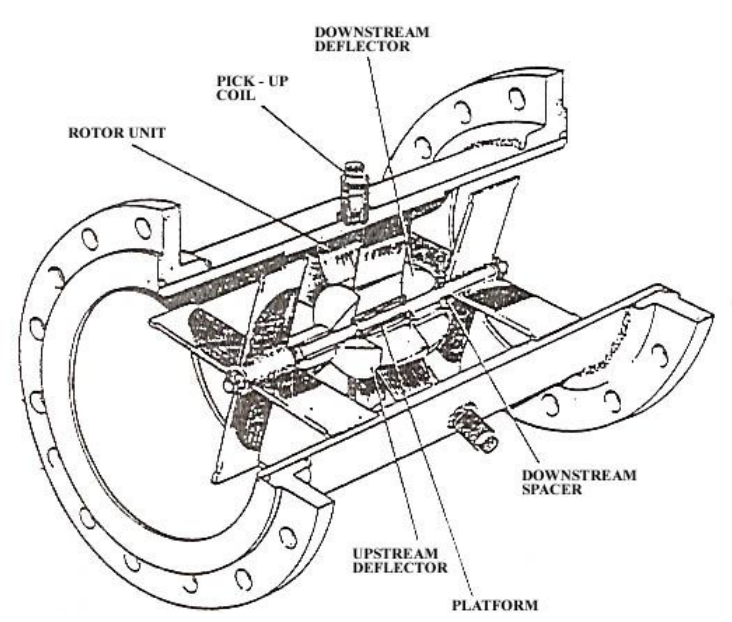

Figure 1. Structure of turbine flowmeter (Korea Water Resources Corporation). 
frequency data of flowmeter, Measurement analysis results of turbine flowmeter showed, that the uncertainty of measurement was increased as the temperature of fuel was decreasing, and fuel pressure and atmospheric pressure would not affect the flow measurement (Yang, 2011).

For calculating the cross sectional area, the velocity of flow, and the quantity of flow the following formular (1), (2), and (3) can be used, respectively.

$$
\begin{aligned}
& A=\left(\frac{\pi}{4}\right) d^{2} \\
& V=\sqrt{2 g} \times P \\
& Q=A \times V
\end{aligned}
$$

where A : cross sectional area, $\mathrm{m}^{2}$

$\mathrm{d}$ : diameter, $\mathrm{m}$

$\mathrm{V}$ : velocity, $\mathrm{m} / \mathrm{s}$

$\mathrm{g}$ : acceleration of gravity, $\mathrm{m} / \mathrm{s}^{2}$

$\mathrm{P}$ : pressure, $\mathrm{kg} / \mathrm{m}^{2}$

$\mathrm{Q}$ : volume flow rate, $\mathrm{m}^{3} / \mathrm{s}$

Therefore, the objectives of this study were to develop an automated disinfectant dilution system for resolving of the problems of less disinfection and more disinfection, and an automated data management system for spraying amount for resolving uncertainty problem whether disinfection had been conducted thoroughly at farm level.

\section{Materials and Methods}

\section{Development of dilution processing system for disinfectant}

In order to make disinfectant have proper dilution rate, a controlled volume pump and a screw conveyer pump were used. Liquid disinfectant was controlled by a controlled volume pump (EWS500, EWHA CHMICAL FEEDER, KOREA; Figure 2), that having $600 \mathrm{~mL}$ of discharge rate, and operated by $220 \mathrm{~V}$ (single phase). Solid disinfectant was controlled by a screw conveyer pump. It was designed and manufactured in this study such as Figure 3 and Figure 4. Its discharge rate was $600 \mathrm{~g}$, and operated by $220 \mathrm{~V}$ (three phase).

A disinfecting system having $400 \mathrm{~L}$ water capacity, was

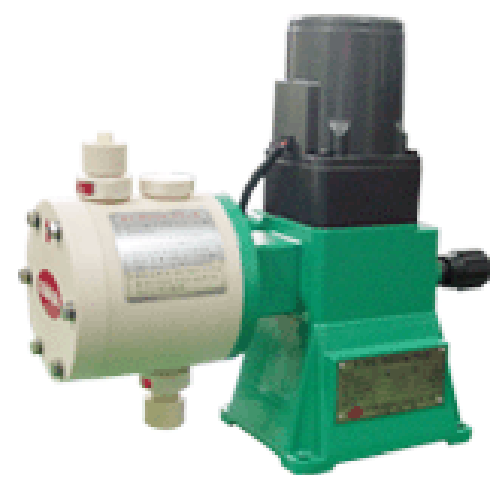

Figure 2. The controlled volume pump used in the experiment.

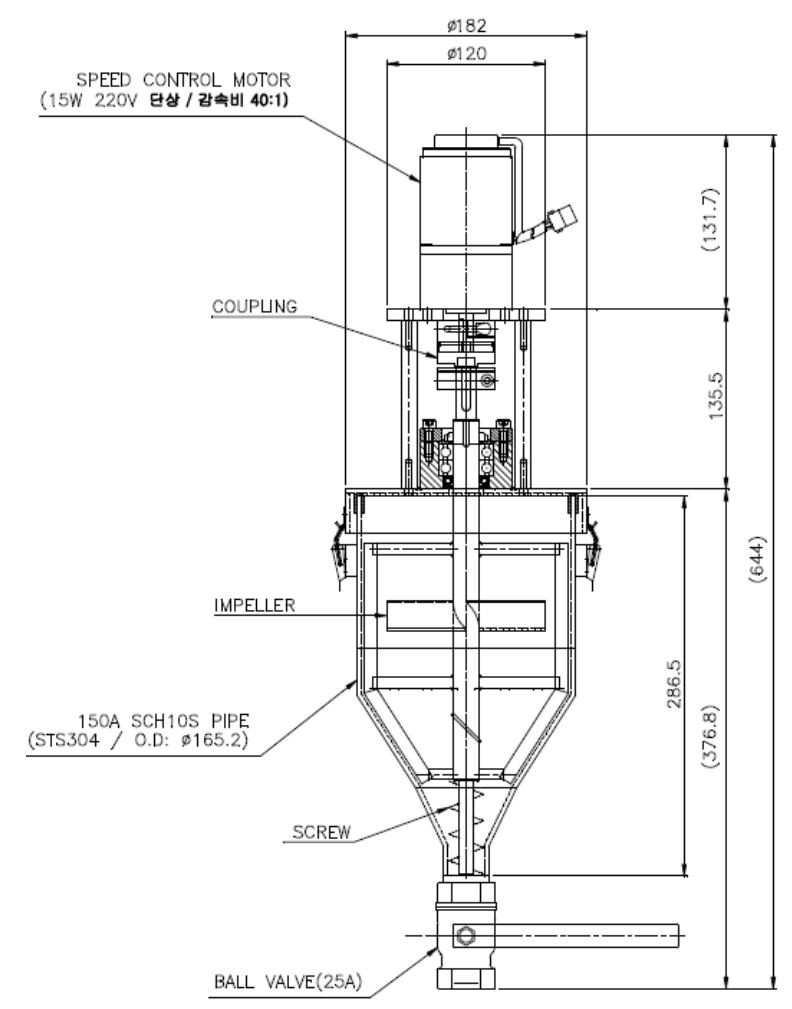

Figure 3. The drawing of screw conveyor pump.
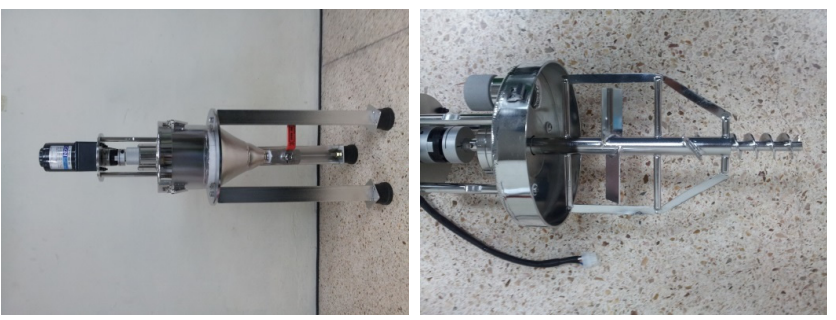

Figure 4. The pictures of the screw conveyor pump developed.

developed to disinfect with a proper dilution rate. Its water capacity of $400 \mathrm{~L}$ was controlled by two water level sensors (OCS-012, ONECHIP SOLUTIONS, KOREA). Water 
level sensors were connected by two wires at terminals and producing signal when the wire was exposed to water. Figure 5 showed the conceptual diagram of water level sensor, and Figure 6 showed the picture of the water level sensor used in the experiment. In order to control

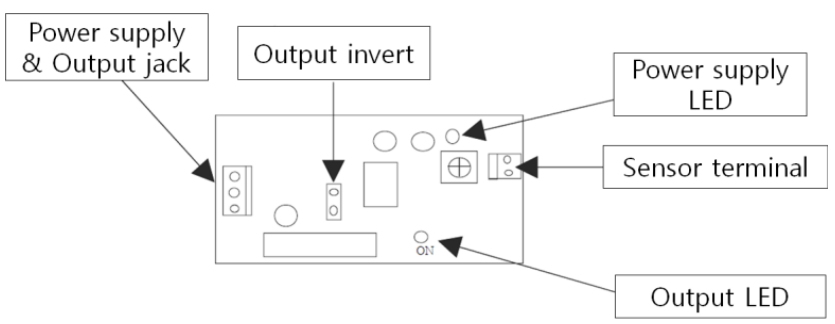

Figure 5. Conceptual diagram of water level sensor.

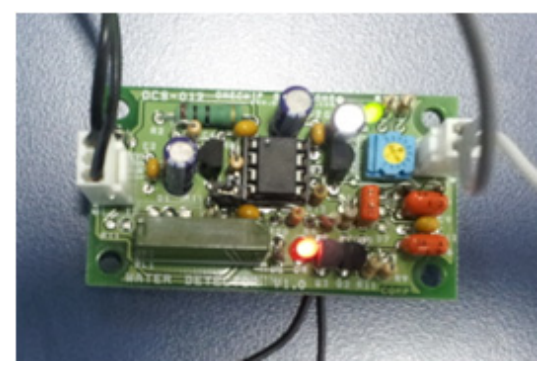

Figure 6. The water level sensor used in the experiment.

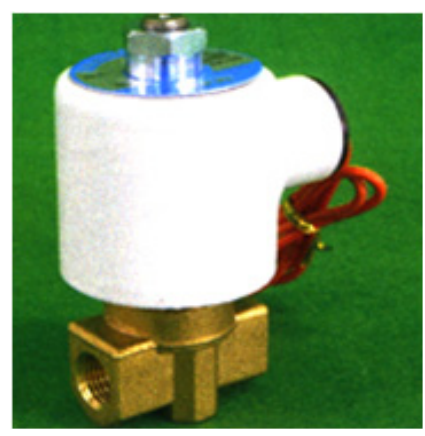

Figure 7. The solenoid valve used in the experiment.

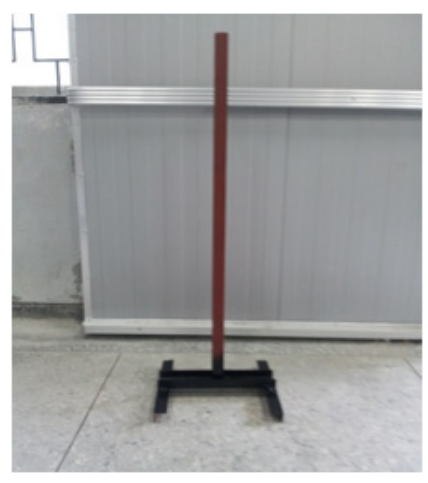

Figure 8. The pedestal for attachment of water level sensor. the water quantity of $400 \mathrm{~L}$, a solenoid valve (Figure 7) was used, which has $41.46 \mathrm{MPa}$ of maximum allowable pressure and operated using $220 \mathrm{~V}$ (single phase). And a pedestal was made to attach the water level sensor as the Figure 8.

For the controlling of equipment, solid state relay (SSR; WYR1C01Z4, WOONYOUNG, KOREA) was used. It utilizes DC $5 \mathrm{~V}$ produced by multi-function data logger, NI USB6008 (National Instruments, USA) for controlling equipment operated by $240 \mathrm{~V}$. Input voltage of SSR is DC $4 \sim 32 \mathrm{~V}$, and output voltage is AC $240 \mathrm{~V}$ (single phase). Figure 9 shows the SSR used in the experiment.

In order to control the operating time of pumps used in the experiment by programming, the operating time of controlled volume pump and screw conveyor pump were controlled and discharge rate was determined accordingly. The water quantity of water tank was controlled by the

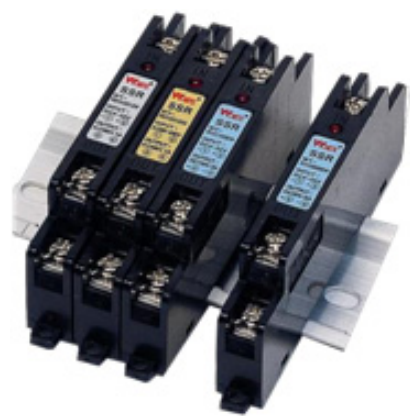

Figure 9. The solid state relay used in the experiment.

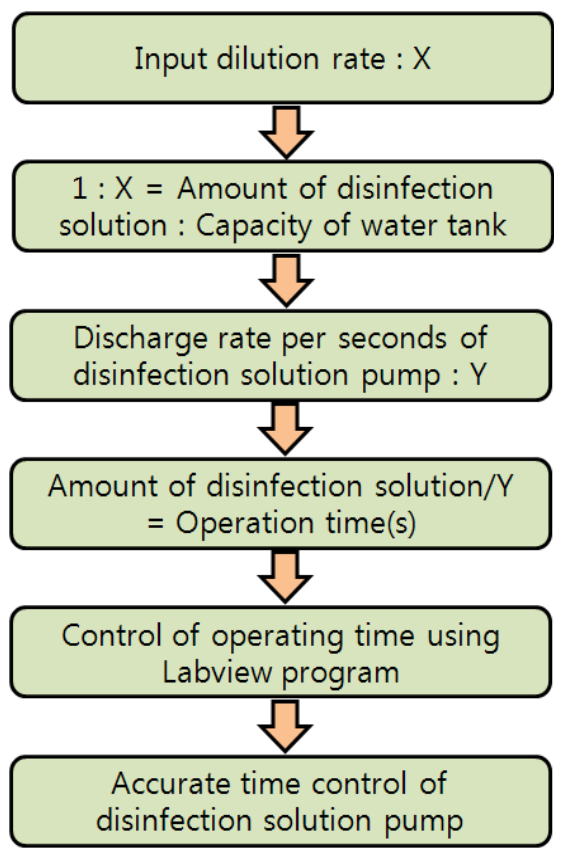

Figure 10. A flow chart of pump time control. 
signals which were produced by the water level sensors attached on the upper level and lower level marked on the pedestal installed on the inside of the water tank. Signals were processed by Labview Programming (National Instruments, USA), and ON/OFF of solenoid valve that was used for controlling water supplying to water tank, was controlled by SSR. The operating time of pumps for disinfectant was controlled quantitatively and Figure 10 showed the flow chart of this control. The controlling programs used in the experiment were programmed by Labview Programming using while-loop, case structure function, array function, and DAQ function and shown in Figure 11, 12, and 13. Figure 11 shows programming for controlling amount of disinfection solution, and Figure 12 for solenoid valve control, and Figure 13 for reading water level sensor.
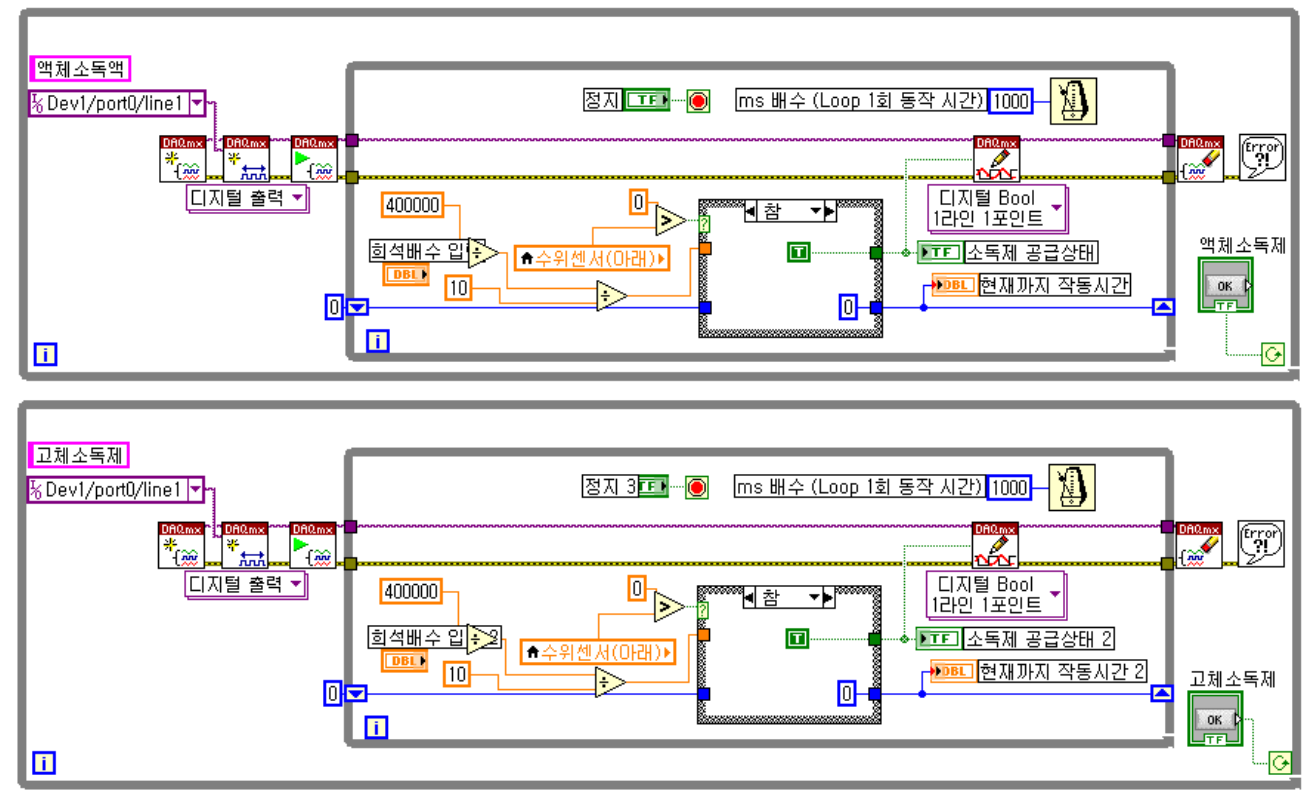

Figure 11. Programming for disinfection solution's amount control (Liquid, Soild).

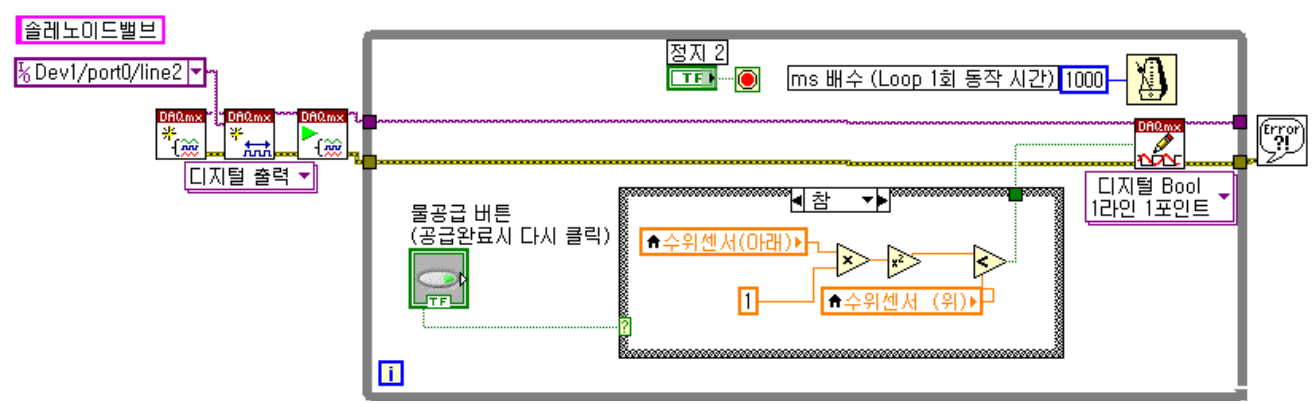

Figure 12. Programming for solenoid valve control.

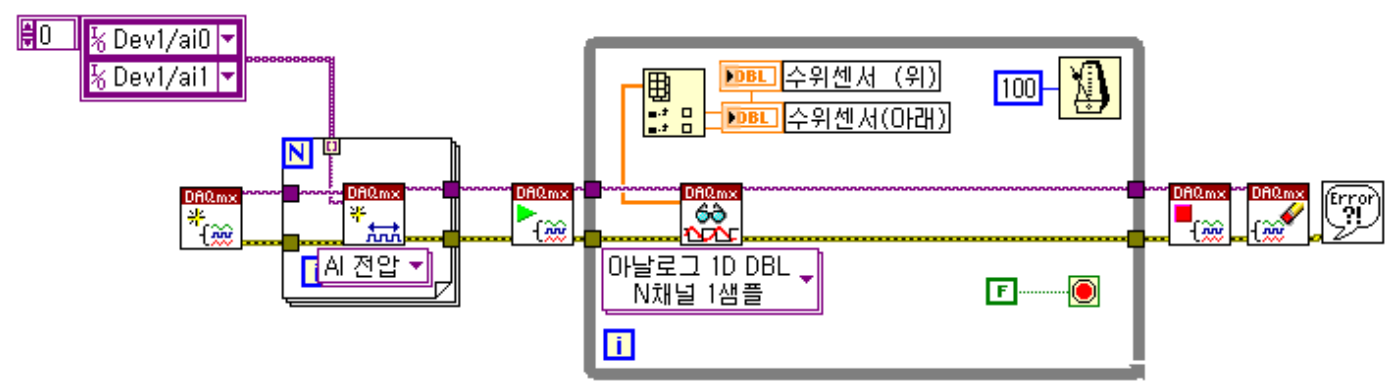

Figure 13. Programming for reading water level sensor. 


\section{Development of automated measurement system for spraying amount of disinfectant}

A turbine flowmeter (GMPS; NURITEC, KOREA) was used for development of automated measurement system for spraying amount of disinfectant, and it was shown in Figure 14. Its specifications are as the followings; capacity is $3.8 \sim 37.9 \mathrm{~L} / \mathrm{min}$, accuracy is $0.5 \%$, maximum allowable pressure is $10.2 \mathrm{MPa}$, minimum measuring amount is $0.01 \mathrm{~L}$ per pulse, and diameter of input and output pipe for hose connection is $1.27 \mathrm{~cm}$, operating voltage is $220 \mathrm{~V}$ (single phase). Figure 15 showed a flowchart of flow data measurement.

Figure 16 showed the overall flow chart and all equipment used of automated measurement system of spraying amount of disinfectant. And Figure 17 showed the diagram of its system for the multi-function data logger and various equipment.

In order to save the flowmeter data and to control the spraying system, a multi-function data logger, NI USB-6008 (National Instruments, USA), was used, which had 8 analog input channels, 2 analog output channels, 12 digital I/O channels, and 32 bit counter function (Figure 18).

Labview 2010 (National Instruments, USA) was used for programming. The flowmeter data was processed and saved in Excel file by a program developed in this study.

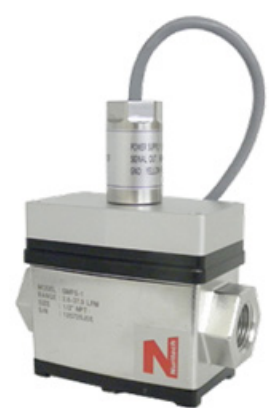

Figure 14. The turbine flowmeter used in the experiment.

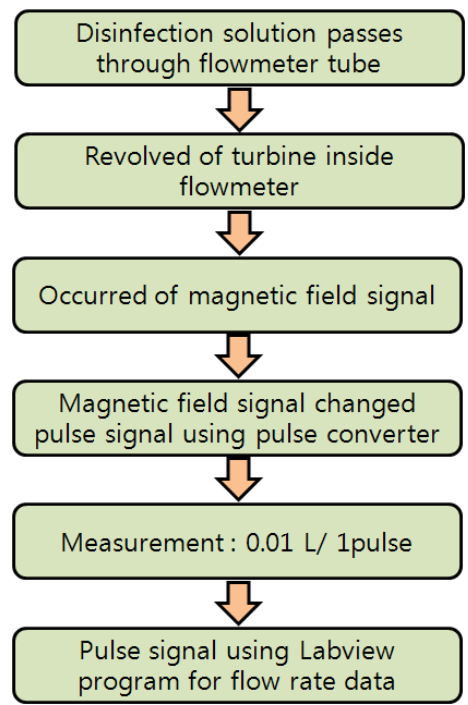

Figure 15. A flow chart of flow data measurement.

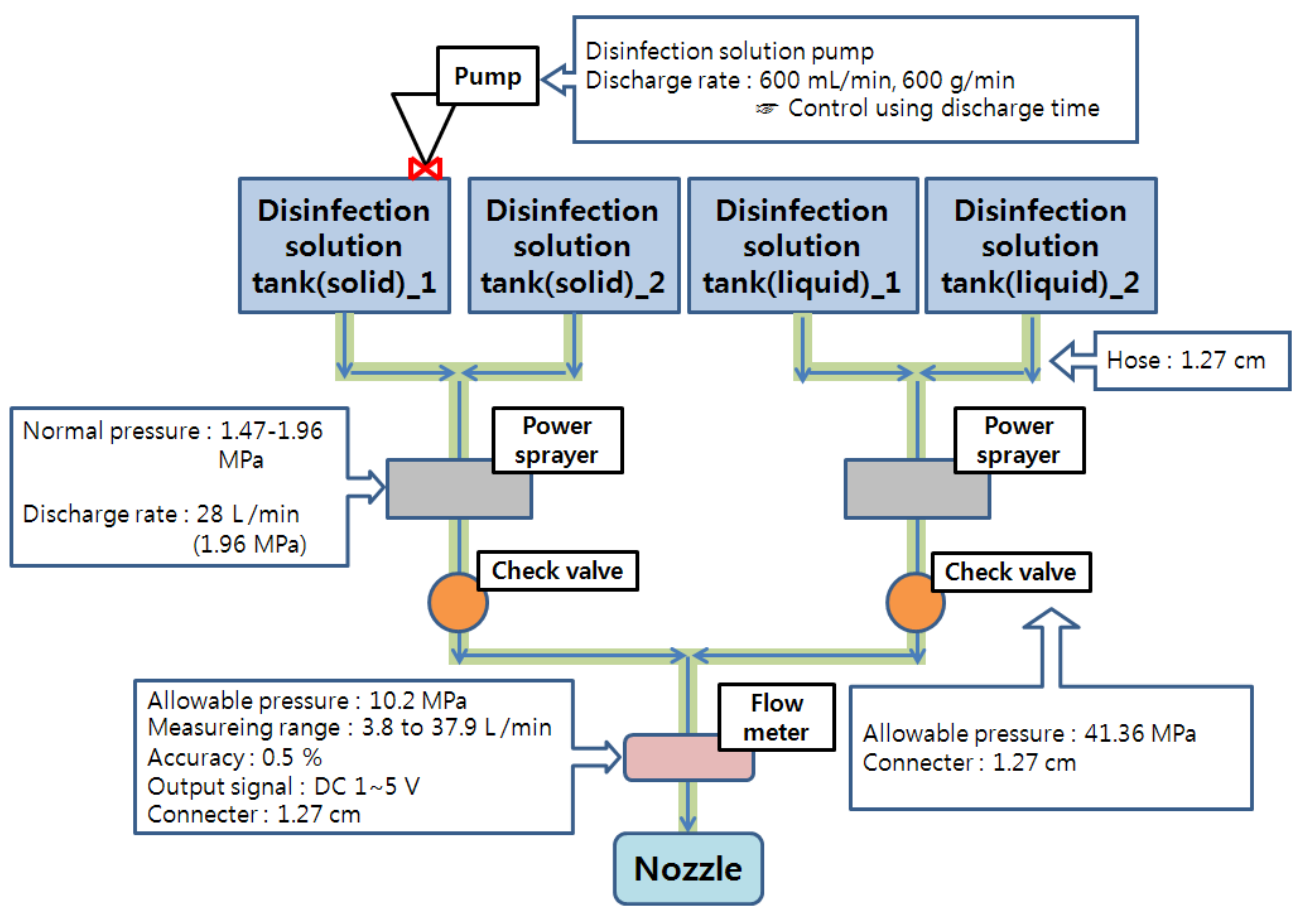

Figure 16. A flow chart of measurement system for disinfectant sprayed. 


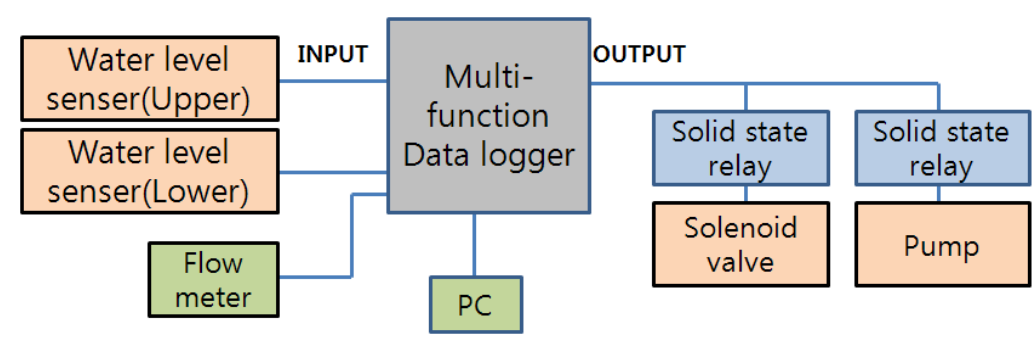

Figure 17. Diagram of system.

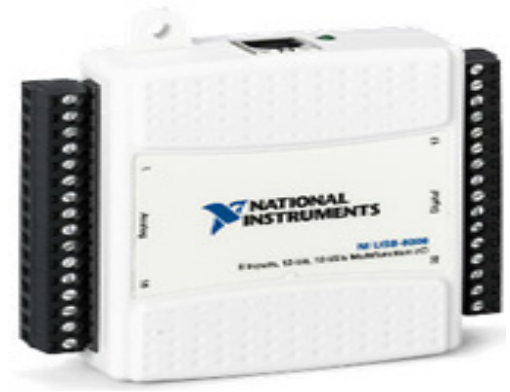

Figure 18. Multi-function data logger used in the experiment.

For programming, While-loop function, time format character function, spreadsheet file writing function, array function etc. were used and it was shown in Figure 19.

\section{Results and Discussions}

\section{Labview programming}

Labview 2010 was used for programming to control the automated measurement system for spraying amount of disinfectant. Figure 20 and 21 showed block diagram and front panel of Labview programming. The usage of the system developed in this study is as the followings. From front panel of Figure 21, select the type of disinfectant to be used at first, then input the value of dilution ratio of disinfectant. If the value of dilution ratio is entered, the operating times of controlled volume pump and screw conveyor pump are determined and discharge rate is set accordingly for dilution ratio. After

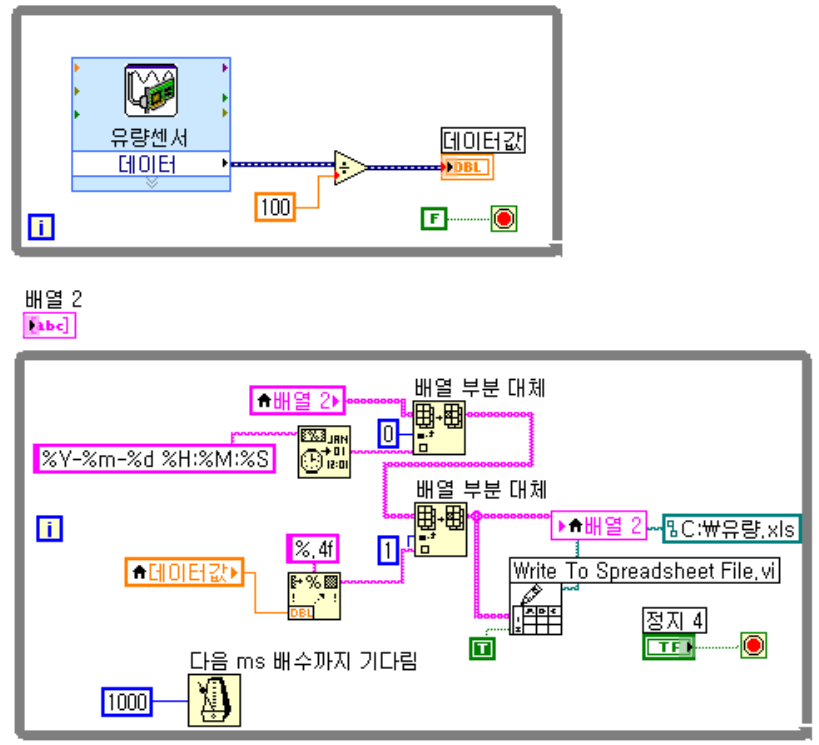

Figure 19. Programming for flowmeter data value.

entering the dilution ratio, if (program run button) is clicked, disinfectant with water is supplied into water tank. Then water suppling button is clicked after water supplying is finished.. Once water supplying is finished, if light for possible-disinfection is on at Front Panel (Figure 21), disinfection operation can be conducted. Data base of spraying amount is saved at $\mathrm{C}: \mathrm{W}$ with file name of [flow-rate.xls] simultaneously.

A prototype of circuit and assembly was made for the experiment and spraying tests were conducted at laboratory of Biosystems Machinery Engineering Department, Chungnam National University as shown in Figure 22.

\section{Comparison of measured spraying amount with flowmeter data}

After testing spraying system, the measured spraying amount was compared with flowmeter data, and the results were shown in Table 1 . Comparison results showed that maximum error was $70 \mathrm{~mL}$; minimum error $10 \mathrm{~mL}$, the average $50 \mathrm{~mL}$, and error range $1.3 \%$. The flowmeter 


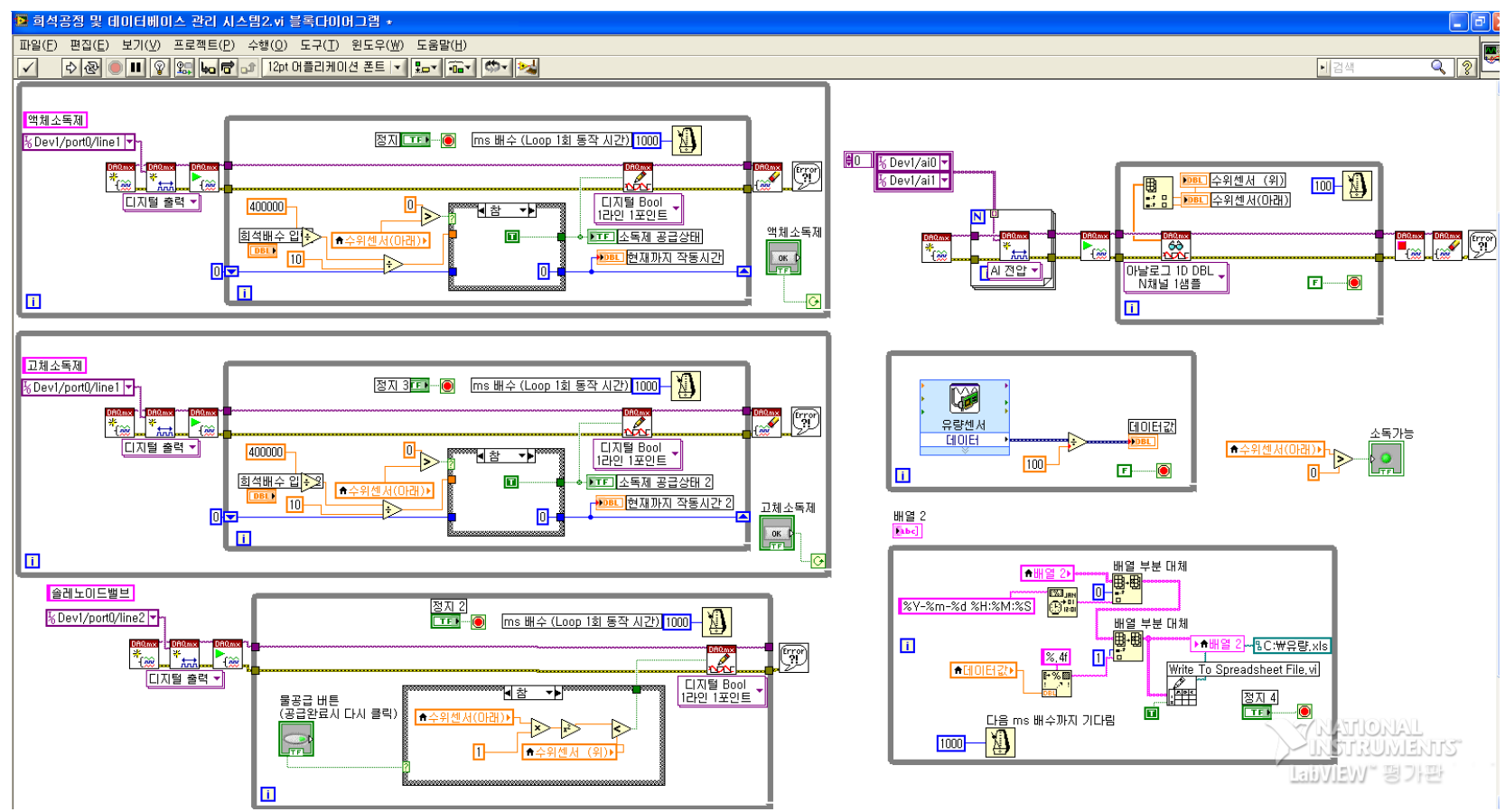

Figure 20. Labview programming(Block diagram).

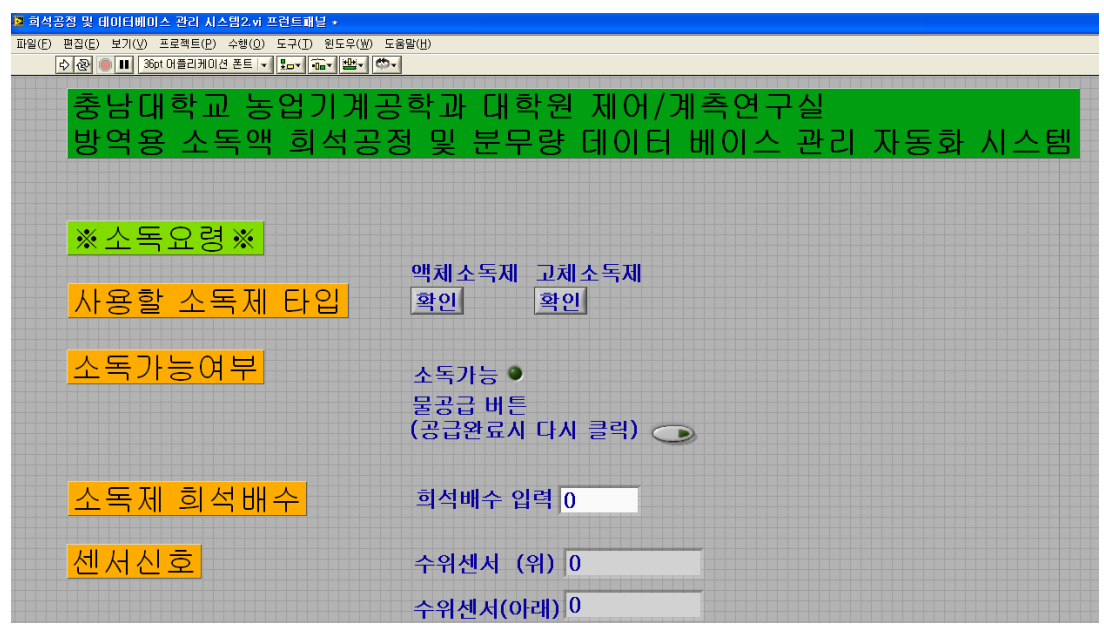

Figure 21. Labview programming(Front panel).

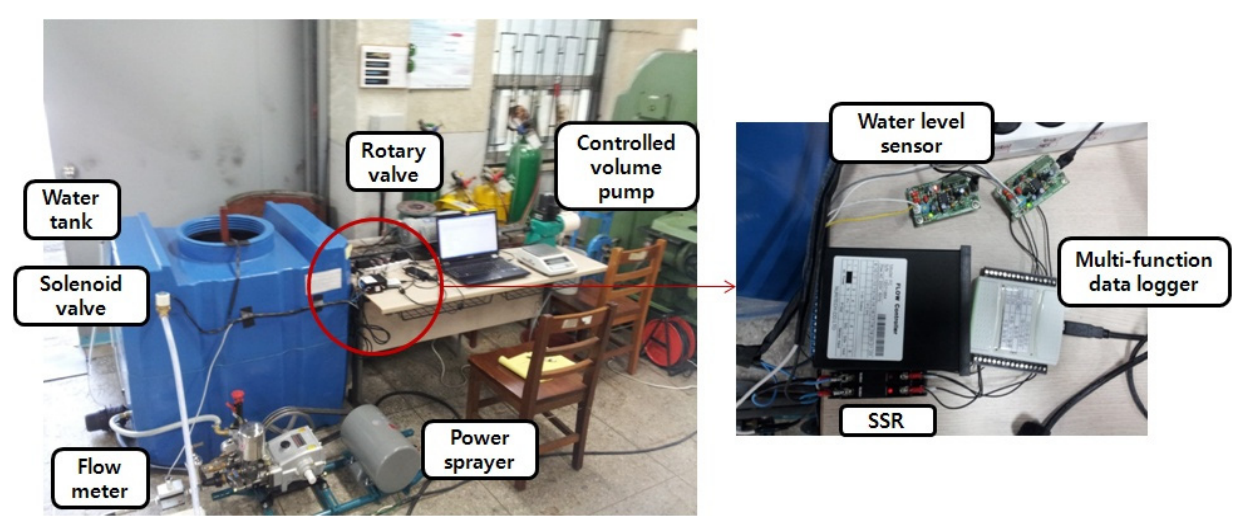

Figure 22. Pictures of the prototype of circuit and assembly made for the experiment. 


\begin{tabular}{|c|c|c|c|}
\hline Item & $\begin{array}{c}\text { Measured } \\
\text { amount }\end{array}$ & $\begin{array}{c}\text { Flow meter } \\
\text { data }\end{array}$ & Error (\%) \\
\hline 1 & 2.79 & 2.81 & 0.72 \\
\hline 2 & 2.92 & 2.95 & 1.03 \\
\hline 3 & 3.40 & 3.45 & 1.47 \\
\hline 4 & 3.53 & 3.56 & 0.85 \\
\hline 5 & 3.58 & 3.62 & 1.12 \\
\hline 6 & 3.66 & 3.72 & 1.64 \\
\hline 7 & 3.71 & 3.78 & 1.89 \\
\hline 8 & 3.72 & 3.78 & 1.61 \\
\hline 9 & 3.90 & 3.97 & 1.79 \\
\hline 10 & 3.93 & 3.98 & 1.27 \\
\hline 11 & 4.01 & 4.06 & 1.25 \\
\hline 12 & 4.29 & 4.34 & 1.17 \\
\hline 13 & 4.30 & 4.36 & 1.40 \\
\hline 14 & 4.36 & 4.40 & 0.92 \\
\hline 15 & 4.49 & 4.50 & 0.22 \\
\hline Average & 3.77 & 3.82 & $1.30^{a}$ \\
\hline
\end{tabular}

${ }^{\mathrm{a}} \mathrm{RMS}$ : Root-mean-square.

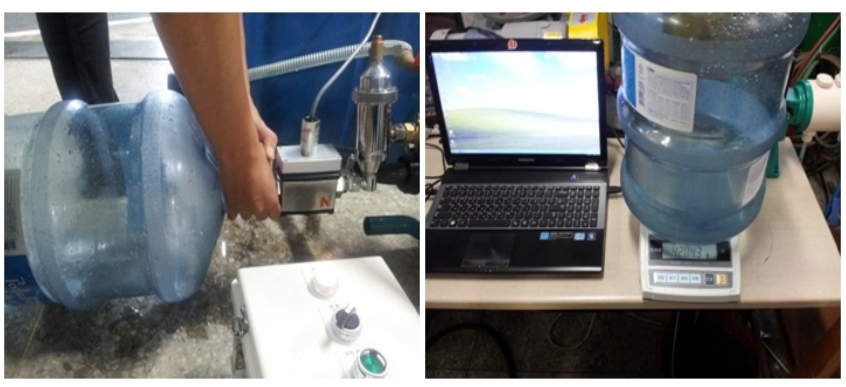

Figure 23. Measurement of measured amount of the disinfectant sprayed.

used in this study was a turbine flowmeter and it was considered that its upstream deflector might turn a little bit even after spraying operation was finished, and it might cause $50 \mathrm{~mL}$ of average error.

Measurement of sprayed amount of disinfectant was carried out as shown in Figure 23. Figure 24 showed the flowmeter data value recorded as Excel file by programming. In the spraying tests, test was carried out for 15 minutes and a regression analysis was conducted as Figure 25. This result showed that the relationship between flowmeter value and time, had a significant linear relationship such as 0.99 of $\mathrm{R}^{2}$.

\begin{tabular}{|c|c|c|}
\hline 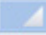 & A & B \\
\hline 1 & 2012-09-04 16:57 & 0 \\
\hline 2 & $2012-09-0416: 57$ & 0 \\
\hline 3 & 2012-09-04 16:57 & 0 \\
\hline 4 & $2012-09-04 \quad 16: 57$ & 0.03 \\
\hline 5 & 2012-09-04 16:57 & 0.29 \\
\hline 6 & $2012-09-0416: 57$ & 0.72 \\
\hline 7 & $2012-09-0416: 57$ & 1.22 \\
\hline 8 & $2012-09-04 \quad 16: 57$ & 1.72 \\
\hline 9 & 2012-09-04 16:57 & 2.22 \\
\hline 10 & $2012-09-0416: 57$ & 2.72 \\
\hline 11 & $2012-09-04 \quad 16: 57$ & 2.81 \\
\hline 12 & 2012-09-04 16:57 & 2.81 \\
\hline 13 & 2012-09-04 16:57 & 2.81 \\
\hline 14 & 2012-09-04 16:57 & 2.81 \\
\hline 15 & $2012-09-0416: 57$ & 2.81 \\
\hline 16 & $2012-09-04 \quad 16: 57$ & 2.81 \\
\hline 17 & $2012-09-0416: 57$ & 2.81 \\
\hline 18 & 2012-09-04 16:57 & 2.81 \\
\hline 19 & $2012-09-04 \quad 16: 57$ & 2.81 \\
\hline 20 & 2012-09-04 16:57 & 2.81 \\
\hline \multicolumn{3}{|l|}{21} \\
\hline \multicolumn{3}{|l|}{22} \\
\hline 23 & בקו & \\
\hline
\end{tabular}

Figure 24. Recording excel file for flowmeter data value.

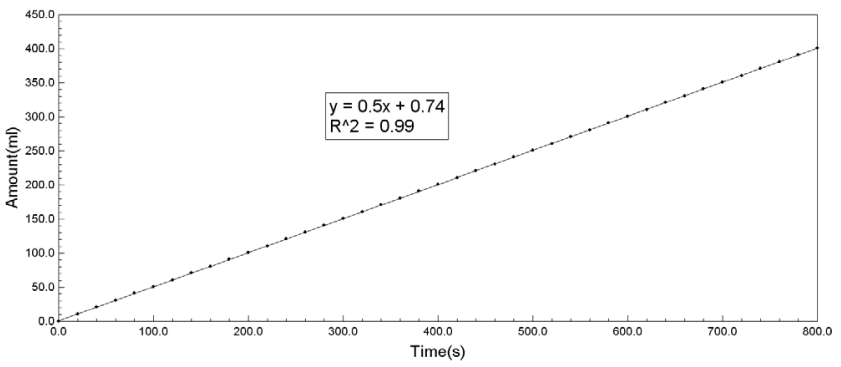

Figure 25. Regression analysis about flowmeter data value.

\section{Comparison of measured amount with theoretical amount for liquid disinfectant pump}

For dilution rate of 200, the comparison results of discharge rate for the controlled volume pump are shown as Table 2. For dilution rate of 200 , the theoretical amount was $2000 \mathrm{~mL}$. There were errors between the measured amount and the theoretical amount. The maximum value of error was $56.5 \mathrm{~mL}$; the minimum 53.6 $\mathrm{mL}$; the average $54.8 \mathrm{~mL}$; the range of average value $2.74 \%$. The capacity of the controlled volume pump used in the test was $600 \mathrm{~mL} / \mathrm{min}$. Since the spraying amount was controlled per second in this test, it was considered that a little amount of error might be caused by the limitation of small quantity.

For dilution rate of 1,200 , Table 3 shows the comparison results of discharge rate for the controlled volume pump. For dilution rate of 1,200 , the theoretical amount was 


\begin{tabular}{|c|c|c|c|}
\hline Repeat Item & $\begin{array}{c}\text { Theoretical } \\
\text { amount }\end{array}$ & $\begin{array}{c}\text { Measured } \\
\text { amount }\end{array}$ & Error (\%) \\
\hline 1 & $2,000.0$ & $2,056.0$ & 2.80 \\
\hline 2 & $2,000.0$ & $2,053.6$ & 2.68 \\
\hline 3 & $2,000.0$ & $2,056.5$ & 2.83 \\
\hline 4 & $2,000.0$ & $2,054.5$ & 2.73 \\
\hline 5 & $2,000.0$ & $2,053.8$ & 2.69 \\
\hline 6 & $2,000.0$ & $2,054.9$ & 2.75 \\
\hline 7 & $2,000.0$ & $2,056.1$ & 2.81 \\
\hline 8 & $2,000.0$ & $2,055.2$ & 2.76 \\
\hline 9 & $2,000.0$ & $2,053.7$ & 2.68 \\
\hline 10 & $2,000.0$ & $2,053.9$ & 2.70 \\
\hline Average & $2,000.0$ & $2,054.8$ & $2.74^{a}$ \\
\hline
\end{tabular}

${ }^{\mathrm{a}} \mathrm{RMS}$ : Root-mean-square.

Table 3. Comparison of measured amount and theoretical amount at dilution rate of 1200 (Unit : $\mathrm{mL} / \mathrm{s})$

\begin{tabular}{|cccc|}
\hline Repeat & $\begin{array}{c}\text { Item } \\
\text { Theoretical } \\
\text { amount }\end{array}$ & $\begin{array}{c}\text { Measured } \\
\text { amount }\end{array}$ & Error (\%) \\
\hline 1 & 333.3 & 333.3 & 0.00 \\
\hline 2 & 333.3 & 332.3 & -0.30 \\
\hline 3 & 333.3 & 332.8 & -0.15 \\
\hline 4 & 333.3 & 338.6 & 1.59 \\
\hline 5 & 333.3 & 331.0 & -0.69 \\
\hline 7 & 333.3 & 338.7 & 1.62 \\
\hline 8 & 333.3 & 332.9 & -0.12 \\
\hline 9 & 333.3 & 330.8 & -0.75 \\
\hline 10 & 333.3 & 332.3 & -0.30 \\
\hline Average & 333.3 & 336.6 & 0.99 \\
\hline
\end{tabular}

${ }^{\mathrm{a}} \mathrm{RMS}$ : Root-mean-square.

$333.3 \mathrm{~mL}$. There were errors between the measured amount and the theoretical amount. The maximum value of error was $5.4 \mathrm{~mL}$; the minimum $0.0 \mathrm{~mL}$; the average 2.2 $\mathrm{mL}$; the range of average value $0.86 \%$. The capacity of the controlled volume pump used in the test was 600 $\mathrm{mL} / \mathrm{min}$. Since the spraying amount was controlled per second in this test, it was considered that a little amount of error might be caused by the limitation of small quantity.

For dilution rate of 5.000, Table 4 shows the comparison results of discharge rate for the controlled volume pump. For dilution rate of 5,000, the theoretical amount was $80.0 \mathrm{~mL}$. There were errors between the measured
Table 4. Comparison of measured amount and theoretical amount at dilution rate of 5000 (Unit : $\mathrm{mL} / \mathrm{s}$ )

\begin{tabular}{|cccc|}
\hline Repeat & $\begin{array}{c}\text { Theoretical } \\
\text { amount }\end{array}$ & $\begin{array}{c}\text { Measured } \\
\text { amount }\end{array}$ & Error (\%) \\
\hline 1 & 80.0 & 83.9 & 4.88 \\
\hline 2 & 80.0 & 83.7 & 4.63 \\
\hline 3 & 80.0 & 82.3 & 2.88 \\
\hline 4 & 80.0 & 82.0 & 2.50 \\
\hline 5 & 80.0 & 78.3 & -2.13 \\
6 & 80.0 & 83.3 & 4.13 \\
\hline 7 & 80.0 & 83.2 & 4.00 \\
\hline 8 & 80.0 & 84.0 & 5.00 \\
\hline 9 & 80.0 & 79.8 & -0.25 \\
10 & 80.0 & 78.9 & -1.37 \\
Average & 80.0 & 81.9 & $3.53^{\mathrm{a}}$ \\
\hline
\end{tabular}

${ }^{\mathrm{a}} \mathrm{RMS}$ : Root-mean-square.
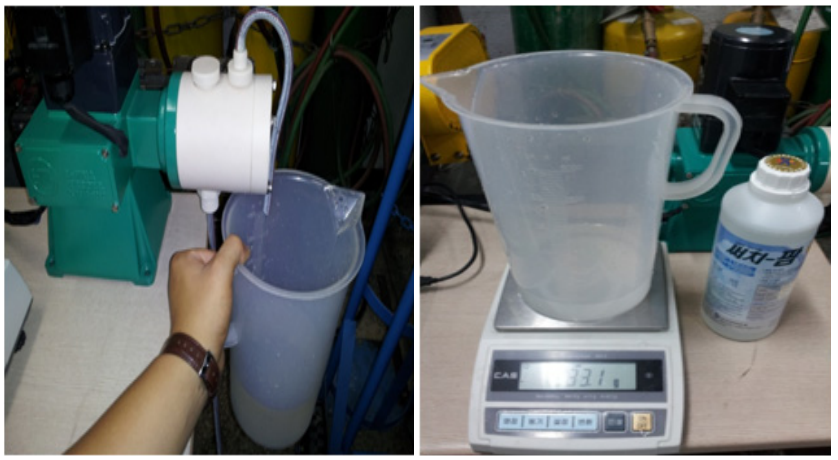

Figure 26. Measurement of controlled volume pump amount.

amount and the theoretical amount. The maximum value of error was $4.0 \mathrm{~mL}$; the minimum $0.2 \mathrm{~mL}$; the average 2.5 $\mathrm{mL}$; the range of average value $3.53 \%$. The capacity of the controlled volume pump used in the test was 600 $\mathrm{mL} / \mathrm{min}$. Since the spraying amount was controlled per second in this test, it was considered that a little amount of error might be caused by the limitation of small quantity. Figure 26 shows the picture of the controlled volume pump test.

\section{Comparison of measured amount with theoretical amount for solid disinfectant pump}

For dilution rate of 200 , Table 5 shows the comparison results of discharge rate for the screw conveyor pump. For dilution rate of 200, the theoretical amount was 2,000 $\mathrm{g}$. There were errors between the measured amount and the theoretical amount. The maximum value of error was $64.6 \mathrm{~g}$; the minimum $24.1 \mathrm{~g}$; the average $47.1 \mathrm{~g}$; the range 
Table 5. Comparison of measured amount and theoretical amount at dilution rate of 200 (Unit : g/s)

\begin{tabular}{|cccc|}
\hline Repeat & Item $\begin{array}{c}\text { Theoretical } \\
\text { amount }\end{array}$ & $\begin{array}{c}\text { Measured } \\
\text { amount }\end{array}$ & Error (\%) \\
\hline 1 & $2,000.0$ & $2,044.6$ & 2.23 \\
\hline 2 & $2,000.0$ & $2,055.4$ & 2.77 \\
\hline 3 & $2,000.0$ & $2,064.6$ & 3.23 \\
\hline 4 & $2,000.0$ & $2,053.5$ & 2.68 \\
\hline 5 & $2,000.0$ & $2,054.5$ & 2.73 \\
\hline 6 & $2,000.0$ & $2,053.2$ & 2.66 \\
\hline 7 & $2,000.0$ & $2,046.2$ & 2.31 \\
\hline 8 & $2,000.0$ & $2,035.1$ & 1.76 \\
\hline 9 & $2,000.0$ & $2,039.3$ & 1.97 \\
\hline 10 & $2,000.0$ & $2,024.1$ & 1.21 \\
Average & $2,000.0$ & $2,047.1$ & $2.42^{\mathrm{a}}$ \\
\hline
\end{tabular}

${ }^{\mathrm{a}} \mathrm{RMS}$ : Root-mean-square.

Table 6. Comparison of measured amount and theoretical amount at dilution rate of 1200 (Unit : g/s)

\begin{tabular}{|c|c|c|c|}
\hline Repeat Item & $\begin{array}{c}\text { Theoretical } \\
\text { amount }\end{array}$ & $\begin{array}{l}\text { Measured } \\
\text { amount }\end{array}$ & Error (\%) \\
\hline 1 & 333.3 & 332.5 & -0.24 \\
\hline 2 & 333.3 & 334.0 & 0.21 \\
\hline 3 & 333.3 & 324.2 & -2.73 \\
\hline 4 & 333.3 & 329.6 & -1.11 \\
\hline 5 & 333.3 & 336.5 & 0.96 \\
\hline 6 & 333.3 & 333.4 & 0.03 \\
\hline 7 & 333.3 & 326.8 & -1.95 \\
\hline 8 & 333.3 & 333.1 & -0.06 \\
\hline 9 & 333.3 & 329.8 & -1.05 \\
\hline 10 & 333.3 & 331.6 & -0.51 \\
\hline Average & 333.3 & 331.2 & $1.22^{a}$ \\
\hline
\end{tabular}

${ }^{\mathrm{a}} \mathrm{RMS}$ : Root-mean-square.

of average value $2.42 \%$. The capacity of the screw conveyor pump used in the test was $600 \mathrm{~g} / \mathrm{min}$. Since the spraying amount was controlled per second in this test, it was considered that a little amount of error might be caused by the limitation of small quantity.

For dilution rate of 1,200 , Table 6 shows the comparison results of discharge rate for the screw conveyor pump. For dilution rate of 1,200 , the theoretical amount was $333.3 \mathrm{~g}$. There were errors between the measured amount and the theoretical amount. The maximum value of error was $9.1 \mathrm{~g}$; the minimum $0.1 \mathrm{~g}$; the average $2.7 \mathrm{~g}$; the range of average value $1.22 \%$. The capacity of the screw conveyor pump used in the test was $600 \mathrm{~g} / \mathrm{min}$. Since the
Table 7. Comparison of measured amount and theoretical amount at dilution rate of 5000 (Unit : g/s)

\begin{tabular}{|cccc|}
\hline Repeat & Item $\begin{array}{c}\text { Theoretical } \\
\text { amount }\end{array}$ & $\begin{array}{c}\text { Measured } \\
\text { amount }\end{array}$ & Error (\%) \\
\hline 1 & 80.0 & 75.5 & -5.63 \\
\hline 2 & 80.0 & 79.9 & -0.12 \\
\hline 3 & 80.0 & 81.1 & 1.37 \\
\hline 4 & 80.0 & 76.2 & -4.75 \\
\hline 5 & 80.0 & 80.9 & 1.13 \\
\hline 6 & 80.0 & 77.8 & -2.75 \\
\hline 7 & 80.0 & 82.5 & 3.13 \\
\hline 8 & 80.0 & 80.4 & 0.50 \\
\hline 9 & 80.0 & 79.5 & -0.63 \\
10 & 80.0 & 83.1 & 3.87 \\
\hline Average & 80.0 & 79.7 & $3.01^{\mathrm{a}}$ \\
\hline
\end{tabular}

${ }^{\mathrm{a}} \mathrm{RMS}$ : Root-mean-square.

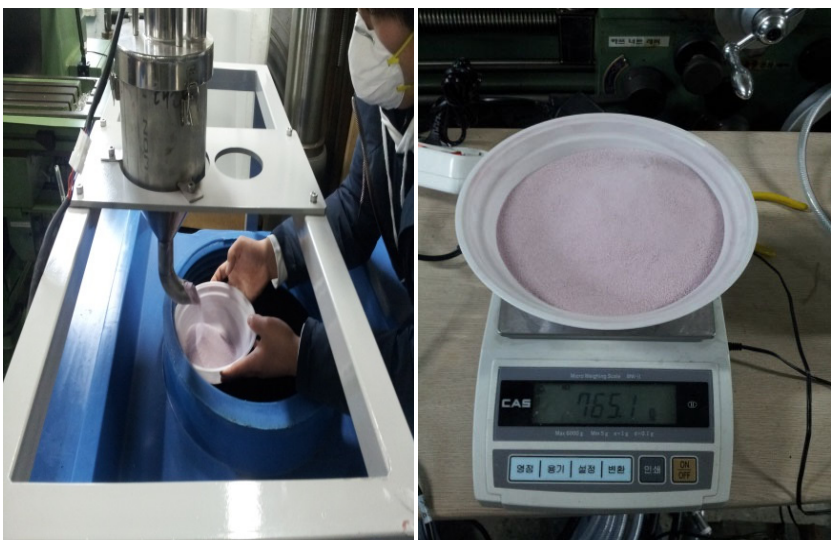

Figure 27. Measurement of controlled screw conveyor pump amount.

spraying amount was controlled per second in this test, it was considered that a little amount of error might be caused by the limitation of small quantity.

For dilution rate of 5,000, Table 7 shows the comparison results of discharge rate for the screw conveyor pump. For dilution rate of 5,000 , the theoretical amount was $80.0 \mathrm{~g}$. There were errors between the measured amount and the theoretical amount. The maximum value of error was $4.5 \mathrm{~g}$; the minimum $0.1 \mathrm{~g}$; the average $1.91 \mathrm{~g}$; the range of average value $3.01 \%$. The capacity of the screw conveyor pump used in the test was $600 \mathrm{~g} / \mathrm{min}$. Since the spraying amount was controlled per second in this test, it was considered that a little amount of error might be caused by the limitation of small quantity. Figure 27 shows the picture of the screw conveyor pump test. 


\section{Conclusions}

Currently, the major diseases occurring in livestock farm domestically are foot-and-mouth disease, brucellosis, swine fever, and AI, and these disease are occurred by various pathogenic organism. Due to those diseases, the compensation expenses of stamping out and the costs of preventive measures of disease have run into astronomical figures. Currently we are experiencing some problems of less disinfection and more disinfection in domestic livestock farms, that are occurring by the improper dilution rate of disinfectant. The less disinfection takes a serious turn of disease, while a more disinfection causes environmental pollution of spraying area, and due to the loss of disinfectant, economical and temporal damages are occurring seriously. Also currently, because foot-andmouth disease and AI are taking serious turn, the livestock farms are conducting disinfection using spraying equipment under the regulation of disinfection. But, there is uncertainty problem whether disinfection has been conducted thoroughly at farm level. Therefore, in this study, an automated disinfectant dilution system and an automated data management system for spraying amount were developed. The study results were concluded as the followings:

(1) Generally, $6.74 \mathrm{~L} / \mathrm{s}$ of diluted disinfectant is sprayed for a vehicle passing through the disinfection system (about 15 seconds). Test results showed that average error between the measured spraying amount and the flowmeter data was $50 \mathrm{~mL}$, and the range of error was $1.3 \%$. Therefore, it could be concluded that the disinfection system would be working accurately, relatively.

(2) Since the amount and time of spraying could be saved in real-time by using the spreadsheet files which could not be modified arbitrarily, it made possible to judge objectively whether the disinfection spraying was performed or not. Therefore, it could be considered that the automated spraying data base management system satisfied the purpose of this study.

(3) Test results of the controlled volume pump for liquid disinfectant and the screw conveyor pump for solid disinfectant showed that the errors between the measured discharge rate and the theoretical one were ranged within 3-4\% for various dilution rates. And it was evaluated that the automated dilution process system developed in this study, could discharge liquid disinfectant and solid disinfectant with accurate dilution rate, relatively.

\section{Conflict of Interest}

The authors have no conflicting financial or other interests.

\section{References}

Cha, C.N., Y.E. Lee, I.J. Kang, C.Y. Yoo, S.J. An, S. Kim and H.J. Lee. 2012. Bactericidal efficacy of vital-oxide, disinfectant solution against salmonella typhimurium and brucella ovis. Journal of Food Hygiene and Safety 27(1):50-54.

Cho, S.R. and S.H. Kahng. 1993. A precise automatic dispenser/diluter controlled by personal computer. Ocean and Polar Research 15(1):71-77.

Kwon, S.I., Y.J. Kim, C.J. Lee and W. Kim. 2009. Discharge measurement using non-contact radar surface velocity meter. Korea Water Resources Association Semiannual May(21):1841-1844.

KSAM. 2012. Agricultural Machinery Yearbook. Korean Society for Agricultural Machinery.

Park, S.J., C.K. Bong and J.J. Lee. 2011. A development of the dilution system for calibration of the electrochemical sensor. Proceeding of KSAE Fall Conference, Korean Society for Atmospheric Environment 10: 250-250.

Yang, I.Y. 2011. Measurement uncertainty analysis of a turbine flowmeter for fuel flow measurement in altitude engine test. Journal of Fluid Machinery 14(1): 42-47.

Korea Water Resources Corporation. 2007. Classification and Characteristics of Flowmeter, K-water Institute, Korea Water Resources Corporation. 